\title{
Use of digitised left ventricular echocardiograms in assessment of mitral stenosis
}

\author{
KEIZO FURUKAWA, TOHRU MATSUURA, NAOTO ENDO, HIROSHI \\ KUNISHIGE, MASARU TOHARA, TOSHIMITSU WATANABE, \\ HARUO MATSUKUBO, YASUHIRO TSUJI, AND HAMAO IJICHI
}

From the Second Department of Medicine, Kyoto Prefectural University of Medicine, Kyoto, and the Department of Cardiology, Matsushita Hospital, Osaka, Fapan

SUMMARY In order to establish a new echocardiographic index of the severity of mitral stenosis, left ventricular echocardiograms were digitised using manual tracing and a computer. The instantaneous left ventricular dimension was measured in 15 patients with mitral stenosis. The peak rate of change of left ventricular dimension (peak $\mathrm{dD} / \mathrm{dt}$ ) and the normalised peak rate (peak $\mathrm{dD} / \mathrm{dt} / \mathrm{D}$ ) during early diastole were significantly lower in mitral stenosis than in normal subjects. Also, the time between the second heart sound and peak $\mathrm{dD} / \mathrm{dt}$ was significantly shorter in patients with mitral stenosis than in normal subjects. Correlation between the mitral valve area calculated from the Gorlin formula and peak $\mathrm{dD} / \mathrm{dt} / \mathrm{D}$ was good, while valve area was poorly correlated with the EF slope of the anterior mitral leaflet echo. It is suggested that by continuous measurement of left ventricular dimension and of its first derivative, the reduced atrioventricular blood flow in mitral stenosis can be shown, and that peak $\mathrm{dD} / \mathrm{dt} / \mathrm{D}$ during early diastole is a possible index of its severity.

There is no doubt that echocardiography is useful and qualitatively reliable in diagnosing mitral stenosis when an adequate recording of both leaflets is obtained. This technique also provides important information for surgeons on the thickness and pliability of the valve leaflets and the size of the left ventricular outflow tract. Several investigators (Segal et al., 1966; Edler, 1967; Effert, 1967; Gustafson, 1967) have claimed that the diastolic EF slope of the anterior mitral leaflet reflects the severity of mitral stenosis. As has previously been reported by others (Mary et al., 1973; Cope et al., 1975; Shiu, 1977), we also have frequently noticed discrepancies in patients with mitral stenosis between echocardiographic data and data obtained invasively by cardiac catheterisation and angiography. We have found that the EF slope is not a sensitive measure of the severity of mitral stenosis and is often misleading in individual patients.

We have used a new index, derived from the rate of change of the left ventricular dimension measured from echocardiograms using a computer-assisted method, which correlates well with the mitral valve area and may be useful in clinical practice.

Received for publication 4 July 1978

\section{Methods}

PATIENTS AND CARDIAC CATHETERISATION Fifteen patients with isolated mitral stenosis were studied by cardiac catheterisation and echocardiography. There were 3 men and 12 women, ranging in age from 26 to 56 years, with a mean age of $38.7 \pm 8.9$ years. Five patients had normal sinus rhythm, and the others were in atrial fibrillation. Ten normal subjects, 9 men and 1 woman, ranging in age from 15 to 31 years, with a mean age of $20.0 \pm 5.9$ years, were also studied echocardiographically. All patients underwent left and right heart catheterisation. The mitral valve area was calculated using the modified Gorlin formula (Cohen and Gorlin, 1972). Cardiac output was estimated by the Fick method. Pulmonary artery wedge and left ventricular pressures were recorded simultaneously and the time delay in retrograde transmission of the wedge pressure pulse was assumed to be $0.05 \mathrm{~s}$ (Yang et al., 1978). The mitral diastolic gradient was measured in early diastole, at end-diastole, and midway between these two points, and the average of these 3 measurements was taken as the mean gradient. This figure was averaged over 5 cardiac cycles. 


\section{ECHOCARDIOGRAPHIC METHODS}

Strip-chart echocardiograms were recorded at $100 \mathrm{~mm} / \mathrm{s}$ paper speed using an Aloka SSD-90 echograph and a $2 \cdot 25 \mathrm{MHz}$ transducer $10 \mathrm{~mm}$ in diameter with a repetition frequency of $1000 / \mathrm{s}$. All subjects were studied in the supine position. In order to obtain a clear continuous recording of the interventricular septum and the left ventricular posterior wall, the transducer was placed in the third or fourth intercostal space at the left sternal border. The ultrasound beam was directed to identify the tip of the anterior mitral leaflet or the chordae just below the mitral leaflets as illustrated in Fig. 1. The electrocardiogram (lead II) and phonocardiogram were recorded simultaneously. These echocardiographic studies were performed less than one month before or after cardiac catheterisation.

\section{ANALYSIS OF ECHOCARDIOGRAMS}

In order to measure the instantaneous left ventricular dimension and to calculate its first derivative $(\mathrm{dD} / \mathrm{dt})$, the echocardiographic tracings were analysed by a computer. The echocardiogram was positioned on a digitising table and a stylus pen was moved along each of the two echoes representing the endocardium of the left ventricular side of the septum and the endocardium of the posterior wall of the left ventricle. Since this pen emitted ultrasonic waves, its position could be sensed by microphone-detectors fitted in the adjacent two sides of the table, and converted into electrical signals representing $\mathrm{X}$ and $\mathrm{Y}$ co-ordinates, with a resolution at $0.17 \mathrm{~mm}$. This information, together with calibration signals corresponding to $10 \mathrm{~cm}, 1 \mathrm{~s}$, and a correction for lack of rectilinearity in position of the echocardiogram on the digitising table, was stored by the HITAC 10-II computer.

Linearly interpolated ordinates of one cardiac cycle was derived, corresponding to each of the two echoes, and then the ordinates of the points representing the left ventricular posterior wall echo were subtracted from those of the interventricular
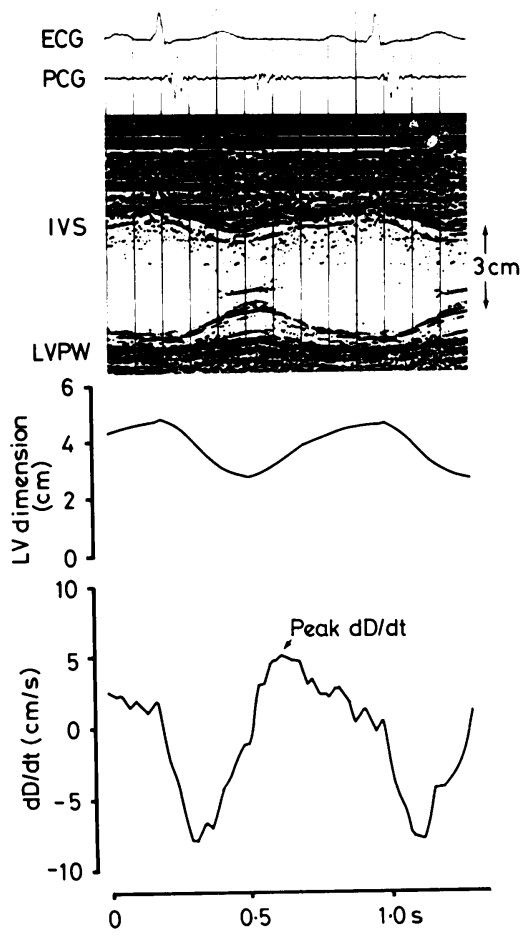

Fig. 1 Electrocardiogram, phonocardiogram, and left ventricular echocardiogram in patient with mitral stenosis (upper). Continuous measurement of left ventricular dimension (middle) and its first derivative $(d D / d t)$ (lower), derived as described in text. ECG, electrocardiogram; PCG, phonocardiogram; IVS, interventricular septum; LVPW, left ventricular posterior wall. Paper speed $100 \mathrm{~mm} / \mathrm{s}$.

septum to give the instantaneous left ventricular dimension (LVD), which was displayed together with its first derivative $(\mathrm{dD} / \mathrm{dt})$ by an $\mathrm{XY}$ plotter (Fig. 1). Nine points least square smoothing was used to compute instantaneous values for the first derivative of the left ventricular dimension. For the present study, the following values were determined:

Table Subjects and echocardiographic data

\begin{tabular}{|c|c|c|c|c|c|c|c|}
\hline & $\begin{array}{l}\text { Age } \\
(y)\end{array}$ & $\begin{array}{l}\text { Heart rate } \\
\text { (beats/min) }\end{array}$ & $\begin{array}{l}\text { End- } \\
\text { diastolic } \\
\text { dimension } \\
(\mathrm{cm})\end{array}$ & $\begin{array}{l}\text { End- } \\
\text { systolic } \\
\text { dimension } \\
(\mathrm{cm})\end{array}$ & $\begin{array}{l}\text { Peak dD/dt } \\
(\mathrm{cm} / \mathrm{s})\end{array}$ & $\begin{array}{l}\text { Peak } \\
d D / d t / D \\
\left(s^{-1}\right)\end{array}$ & $\begin{array}{l}\text { A2-peak } \\
d D / d t \text { time } \\
\text { (ms) }\end{array}$ \\
\hline Normal $(n=10)$ & $20 \cdot 0 \pm 5 \cdot 9$ & $63.6 \pm 10.0$ & $4 \cdot 3 \pm 0 \cdot 3$ & $2 \cdot 8 \pm 0 \cdot 1$ & $10 \cdot 66 \pm 1 \cdot 32$ & $3.33 \pm 0.29$ & $84 \cdot 0 \pm 17 \cdot 4$ \\
\hline Mitral stenosis $(n=15)$ & $38 \cdot 7 \pm 8 \cdot 9^{\star}$ & $70 \cdot 5 \pm 11 \cdot 0$ & $4.5 \pm 0.5$ & $3 \cdot 0 \pm 0 \cdot 4$ & $5 \cdot 89 \pm 1 \cdot 74^{\star}$ & $1.76 \pm 0.64^{\star}$ & $56 \cdot 0 \pm 17 \cdot 8 \star$ \\
\hline
\end{tabular}

A2, aortic component of the second heart sound; Peak $\mathrm{dD} / \mathrm{dt}$; peak rate of change of left ventricular dimension in early diastole; Peak $\mathrm{dD} / \mathrm{dt} / \mathrm{D}$, normalised peak rate of change of left ventricular dimension.

All measurements shown as mean \pm SD. $\star$ Statistical significance of difference from normal group $(P<0.001)$. 


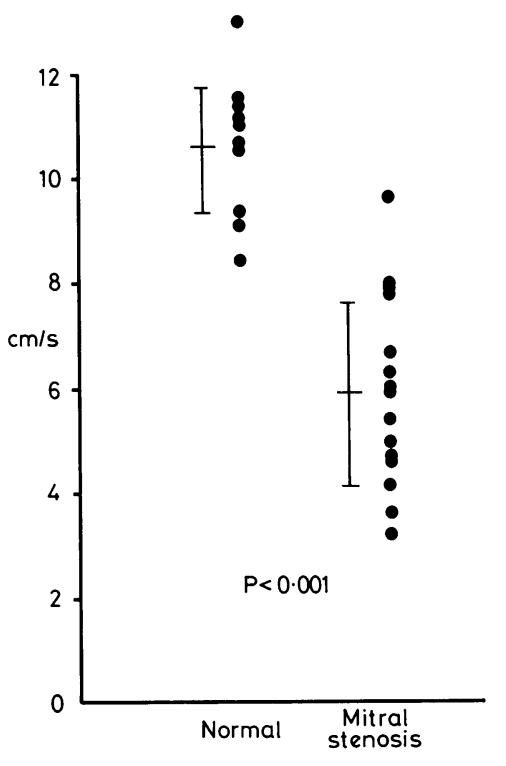

Fig. 2 Peak $d D / d t$. Values shown for individual patients, with mean $\pm S D$. This index was significantly lower in mitral stenosis than in normal subjects $(P<0.001)$.

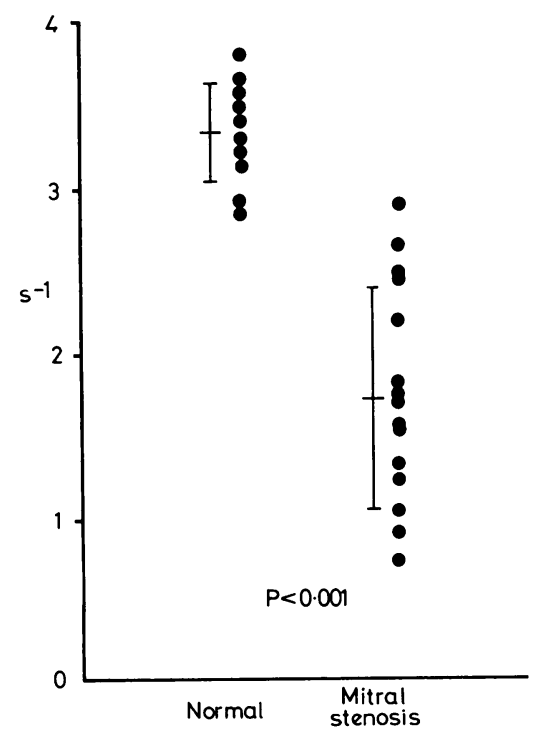

Fig. 3 Peak dD/dt/D. Values shown for individual patients with mean $\pm S D$. This was also significantly reduced in mitral stenosis $(P<0.001)$. The values in patients with mitral stenosis were approximately half of those in normal subjects.
(1) Left ventricular end-diastolic and endsystolic dimension in $\mathrm{cm}$.

(2) The peak rate of change of left ventricular dimension (peak $\mathrm{dD} / \mathrm{dt}$ ) and the normalised peak rate (peak $\mathrm{dD} / \mathrm{dt} / \mathrm{D}$ ) during early diastole in $\mathrm{cm} / \mathrm{s}$ and $\mathrm{s}^{-1}$, respectively. Peak $\mathrm{dD} / \mathrm{dt} / \mathrm{D}$ was obtained by dividing peak $\mathrm{dD} / \mathrm{dt}$ by the instantaneous dimension at which it occurred and read directly from the print-out.

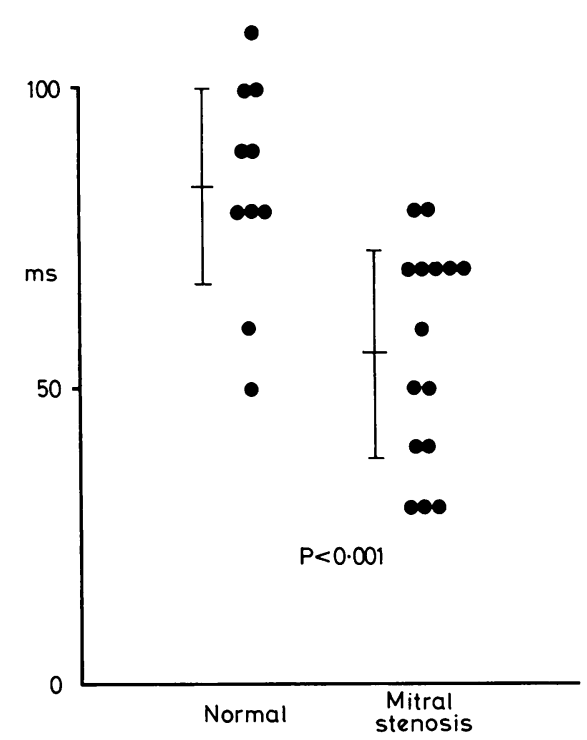

Fig. 4 A2-peak $d D / d t$ time. This time was significantly shorter in mitral stenosis than in normal subjects $(P<0.001)$, and always shorter than A2-OS time.

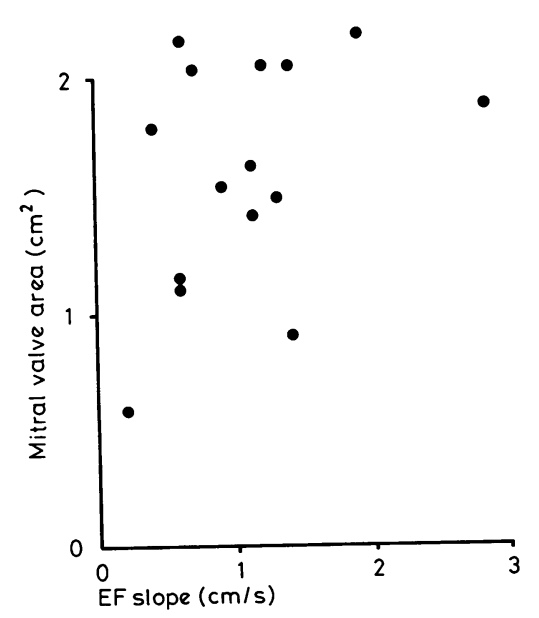

Fig. 5 Mitral valve area vs EF slope. The EF slope correlates poorly with the calculated mitral valve area $(r=0 \cdot 44)$. 
(3) The time between the aortic component of the second heart sound and the peak $\mathrm{dD} / \mathrm{dt}$ in $\mathrm{ms}$ (A2-peak $\mathrm{dD} / \mathrm{dt}$ time).

Student's $\mathrm{t}$ test to determine statistical significance was performed, and the $P$ values less than 0.05 were considered statistically significant.

\section{Results}

\section{NORMAL SUBJECTS}

In the normal group, the mean heart rate was $63.6 \pm 10.0$ beats $/ \mathrm{min}$, the left ventricular enddiastolic dimension was $4.3 \pm 0.3 \mathrm{~cm}$, and endsystolic dimension was $2 \cdot 8 \pm 0.1 \mathrm{~cm}$. Peak $\mathrm{dD} / \mathrm{dt}$ during early diastole was $10.66 \pm 1.32 \mathrm{~cm} / \mathrm{s}$ and peak $\mathrm{dD} / \mathrm{dt} / \mathrm{D} 3.33 \pm 0.29 \mathrm{~s}^{-1}$, and this occurred $84 \cdot 0 \pm 17 \cdot 4 \mathrm{~ms}$ after aortic closure (A2-peak $\mathrm{dD} / \mathrm{dt}$ time). These results are given in detail in the Table.

\section{MITRAL STENOSIS}

The most striking abnormality in this group was a reduction in the peak rate of change of the left ventricular dimension during early diastole (peak $\mathrm{dD} / \mathrm{dt}$ ) to $5.89 \pm 1.74 \mathrm{~cm} / \mathrm{s}$ and peak $\mathrm{dD} / \mathrm{dt} / \mathrm{D}$ to $1 \cdot 76 \pm 0.64 \mathrm{~s}^{-1}$ compared with normal subjects $(\mathrm{P}<0.001)$ (Fig. 2, 3). A2-peak $\mathrm{dD} / \mathrm{dt}$ time was $56.0 \pm 17.8 \mathrm{~ms}$ and was also significantly shorter than in normal subjects $(P<0.001)$ (Fig. 4). Heart rate, left ventricular end-diastolic, and endsystolic dimension were $70.5 \pm 11.0$ beats $/ \mathrm{min}$, $4.5 \pm 0.5 \mathrm{~cm}$, and $3.0 \pm 0.4 \mathrm{~cm}$, respectively. These values did not differ significantly from those in normal subjects.

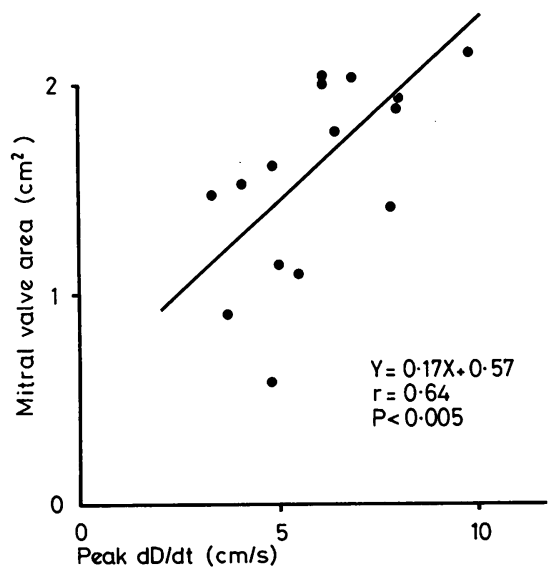

Fig. 6 Mitral valve area vs peak dD/dt. Correlation between the calculated mitral valve area and peak $d D / d t$ was somewhat better $(r=0.64)$, but there was a relatively wide scatter particularly in patients with mitral valve area less than $1.5 \mathrm{~cm}^{2}$.

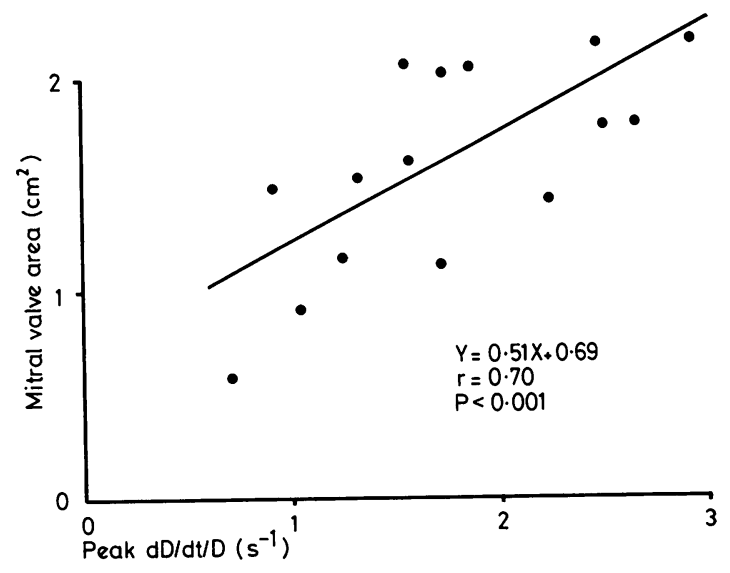

Fig. 7 Mitral valve area vs peak dD/dt/D. There was fairly good correlation between the mitral valve area and peak $d D / d t / D$ during early diastole $(r=0 \cdot 70)$.

CORRELATIONS BETWEEN ECHOCARDIOGRAPHIC AND CARDIAC CATHETERISATION DATA

The calculated mitral valve area (MVA) ranged from 0.6 to $2.2 \mathrm{~cm}^{2}$, and the EF slope of the anterior mitral leaflet from 0.2 to $2.8 \mathrm{~cm} / \mathrm{s}$. The EF slope correlated poorly with the calculated mitral valve area ( $r=0.44)$ (Fig. 5). In the same patients, the correlation between the peak rate of change of the left ventricular dimension (peak $\mathrm{dD} / \mathrm{dt}$ ) and the calculated mitral valve area was better $(r=0.64)$ (Fig. 6); however, there was a relatively wide scatter in patients with a mitral valve area less than $1.5 \mathrm{~cm}^{2}$. There was much better correlation when peak $\mathrm{dD} / \mathrm{dt}$ was related to the instantaneous dimension) (Fig. 7); the regression equation was:

$$
\text { MVA }=0.51 \times \text { peak } \mathrm{dD} / \mathrm{dt} / \mathrm{D}+0.69(\mathrm{r}=0.70) .
$$

\section{Discussion}

Since the initial description of the echocardiographic abnormalities in patients with mitral stenosis (Edler, 1955), numerous reports have appeared. Edler observed that the diastolic EF slope of the anterior mitral leaflet in patients with mitral stenosis was conspicuously reduced compared with normal subjects. Several investigators (Segal et al., 1966; Edler, 1967; Effert, 1967; Gustafson, 1967) found that this EF slope was quantitatively related to the severity of stenosis and the mobility of the valve. However, more recent investigations have shown a poor correlation between the EF slope and the severity of stenosis evaluated at cardiac catheterisation (Cope et al., 1975), and it has been suggested that while the echocardiogram is a reliable method of diagnosing mitral stenosis 
the EF slope is an unreliable index of the severity of this lesion. Because the EF slope does not provide a satisfactory quantitative index of the severity of mitral stenosis, we studied the rate of change of the left ventricular dimension as a measure of the rate of ventricular filling, and tried to evaluate this as an index of severity. It has been shown that there is a close correlation between echocardiographic and angiographic measurements of ventricular filling in patients with a variety of forms of heart disease, and that changes in the echocardiographic left ventricular dimension may be taken as an index of ventricular filling (Gibson and Brown, 1973, 1975). This method has also been used to assess diastolic function of the left ventricle in patients with hypertrophic cardiomyopathy, in which slow ventricular filling has been shown (St. John Sutton et al., 1978), and to study the genesis of the third heart sound (Furukawa et al., 1977). Using this method of measurement of the rate of left ventricular filling, we found that peak $\mathrm{dD} / \mathrm{dt}$ in early diastole, occurring at the time of peak atrioventricular flow, was reduced in patients with mitral stenosis to a half of that in normal subjects. We also found that peak $\mathrm{dD} / \mathrm{dt}$ occurred earlier in patients with mitral stenosis than in normal subjects. This A2-peak $\mathrm{dD} / \mathrm{dt}$ time was always 10 to $60 \mathrm{~ms}$ less than A2-OS time. These results suggest that in mitral stenosis, peak ventricular filling rate is much reduced and that this peak occurs before the opening snap. Our results confirm those of Gibson and Brown (1973) in showing that this technique is useful for evaluating ventricular filling.

The correlations between the echocardiographic indices, peak $\mathrm{dD} / \mathrm{dt}$ and peak $\mathrm{dD} / \mathrm{dt} / \mathrm{D}$, and the calculated mitral valve area were fairly good. The correlation coefficient between peak $\mathrm{dD} / \mathrm{dt} / \mathrm{D}$ and valve area was highest $(r=0 \cdot 70)$, and we suggest that this measurement may be a valid index of the severity of mitral stenosis. On the other hand, the EF slope of the anterior mitral leaflet echo correlated poorly with the calculated mitral valve area $(r=0.44)$. In mitral stenosis, the valve leaflets are thickened and rigid, fused at their commissures, attached to thickened chordae, and often calcified. After opening, the valve leaflets probably move little relative to the valve ring, and the EF slope of the anterior mitral leaflet is thought to be profoundly influenced by mitral ring movement (Zaky et al., 1968; Chakorn et al., 1972). This view is supported by the analogous motion of the cage of a mitral prosthetic valve which is a rigid structure sutured to the valve ring. The rate of diastolic descent of the cage and ball is much reduced in the absence of significant obstruction across the prosthesis. If the movement of the anterior mitral leaflet in mitral stenosis is indeed related to movement of the valve ring, it is not surprising that the EF slope has little relation to the mitral valve area (Mary et al., 1973; Cope et al., 1975; Shiu, 1977).

Because of the unreliability of the EF slope as a measure of the severity of mitral stenosis, Shiu (1977) proposed another index. He derived a mitral valve closure index calculated from the rate of approximation of the anterior and posterior mitral leaflets, and found that this was closely related to the severity of mitral stenosis. Though the posterior mitral leaflet moves anteriorly during diastole in most patients with mitral stenosis, it moves posteriorly in some patients, as in normal subjects. Furthermore, identification of the posterior mitral leaflet is difficult in some cases of mitral stenosis. In these cases, Shiu's index may be inaccurate. Strunk et al. (1977) tried to assess the severity of mitral stenosis and prosthetic mitral valve obstruction from the posterior aortic wall echo. They derived an atrial emptying index from this echo and found that it correlated well with the calculated mitral valve area; this index was also useful in detecting dysfunction of the prosthetic mitral valve.

In this study we used the Gorlin formula. However, this may be a possible source of inaccuracy, particularly as the pulmonary artery wedge pressure was measured as a substitute for direct measurement of left atrial pressure. Resulting errors in calculation of mitral valve area may reduce the correlation between echocardiographic and haemodynamic indices of severity. Diastolic filling rate may be difficult to measure in those patients with severe mitral stenosis and abnormal septal movement (Weyman et al., 1977), and may not measure severity of mitral stenosis in those with impaired left ventricular function who show an abnormal left contraction and relaxation pattern in the posterobasal area of the left ventricle (Heller and Carleton, 1970), and in the presence of other valve lesions. However, in other patients measurement of peak $\mathrm{dD} / \mathrm{dt} / \mathrm{D}$ was useful for evaluating the severity of mitral stenosis. The computer-assisted technique used in this study to obtain instantaneous measurement of the left ventricular dimension with its rate of change was quick and simple to carry out.

We agree with previous authors (Mary et al., 1973; Cope et al., 1975; Shiu, 1977) that the EF slope of the anterior mitral leaflet echo is an unreliable index of the severity of mitral stenosis. On the other hand, in the present study the rate of change of left ventricular dimension reflected the functional haemodynamic disturbance in mitral stenosis. Furthermore, the normalised peak rate of change of this dimension (peak $\mathrm{dD} / \mathrm{dt} / \mathrm{D}$ ) in early diastole correlated well with the calculated mitral 
valve area, and may, therefore, be a reliable predictor of the severity of mitral stenosis.

\section{References}

Chakorn, S. A., Siggers, D. C., Wharton, C. F. P., and Deuchar, D. C. (1972). Study of normal and abnormal movements of mitral valve ring using reflected ultrasound. British Heart fournal, 34, 480-486.

Cohen, M. V., and Gorlin, R. (1972). Modified orifice equation for the calculation of mitral valve area. American Heart fournal, 84, 839-840.

Cope, G. D., Kisslo, J. A., Johnson, M. L., and Behar, V. S. (1975). A reassessment of the echocardiogram in mitral stenosis. Circulation, 52, 664-670.

Edler, I. (1955). The diagnostic use of ultrasound in heart disease. Acta Medica Scandinavica, Suppl. 308, 32.

Edler, I. (1967). Ultrasoundcardiography in mitral stenosis. American fournal of Cardiology, 19, 18-31.

Effert, S (1967). Pre- and post-operative evaluation of mitral stenosis by ultrasound. American fournal of Cardiology, 19, 59-65.

Furukawa, K., Matsuura, T., Endo, N., Tohara, M., Asayama, J., Watanabe, T., Matsukubo, H., and Ijichi, H. (1977). The study of the third heart sound in relation to the left ventricular filling and wall movement by echocardiography. Fapanese Heart fournal, 18, 611-620.

Gibson, D. G., and Brown, D. (1973). Measurement of instantaneous left ventricular dimension and filling rate in man, using echocardiography. British Heart fournal, 35, 1141-1149.

Gibson, D. G., and Brown, D. J. (1975). Measurement of peak rates of left ventricular wall movement in man. Comparison of echocardiography with angiography. British Heart fournal, 37, 677-683.

Gustafson, A. (1967). Correlation between ultrasound cardiography, hemodynamic, and surgical findings in mitral stenosis. American Fournal of Cardiology, 19, 32-41.
Heller, S. J., and Carleton, R. A. (1970). Abnormal left ventricular contraction in patients with mitral stenosis. Circulation, 42, 1099-1110.

Mary, D. A. S., Pakrashi, B. C., Wooler, G. H., and Ionescu, M. I. (1973). Study with reflected ultrasound of patients with mitral valve repair. British Heart fournal, 35, 480-487.

St. John Sutton, M. G., Tajik, A. J., Gibson, D. G., Brown, D. J., Seward, J. B., and Giuliani, E. R. (1978). Echocardiographic assessment of left ventricular filling and septal and posterior wall dynamics in idiopathic hypertrophic subaortic stenosis. Circulation, 57, 512-520.

Segal, B. L., Likoff, W., and Kingsly, B. (1966). Echocardiography. Clinical application in mitral stenosis. Fournal of the American Medical Association, 195, 161-166.

Shiu, M. F. (1977). Mitral valve closure index. Echocardiographic index of severity of mitral stenosis. British Heart fournal, 39, 839-843.

Strunk, B. L., London, E. J., Fitzgerald, J., Popp, R. L., and Barry, W. H. (1977). The assessment of mitral stenosis and prosthetic mitral valve obstruction, using the posterior aortic wall echocardiogram. Circulation, 55, 885-891.

Weyman, A. E., Heger, J. J., Kronik, G., Wann, L. S., Dillon, J. C., and Feigenbaum, H. (1977). Mechanism of paradoxical early diastolic septal motion in patients with mitral stenosis. A cross-sectional echocardiographic study. American fournal of Cardiology, 40, 691-699.

Yang, S. S., Bentivoglio, L. G., Maranhão, V., and Goldberg, H. (1978). Basic measurement and calculations. In From Cardiac Catheterization Data to Hemodynamic Parameters, 2nd edn., pp. 42-45. F. A. Davis, Philadelphia.

Zaky, A., Nasser, W. K., and Feigenbaum, H. (1968). Study of mitral valve action recorded by reflected ultrasound and its application in the diagnosis of mitral stenosis. Circulation, 37, 789-799.

Requests for reprints to Dr Keizo Furukawa, The Second Department of Medicine, Kyoto Prefectural University of Medicine, Kawaramachi-Hirokoii. Kamigyo-ku, Kyoto 602, Japan. 